\author{
DA ELABORAÇÃO AO USO DE VÍDEOS DIDÁTICOS BASEADOS NA \\ HISTÓRIA DA MATEMÁTICA: CARACTERÍSTICAS E SUGESTÕES A \\ PARTIR DE UMA EXEMPLIFICAÇÃO
}

\author{
FROM THE PREPARATION TO THE USE OF DIDACTIC VIDEOS BASED \\ ON THE HISTORY OF MATHEMATICS: CHARACTERISTICS AND \\ SUGGESTIONS FROM AN EXEMPLIFICATION
}

\author{
Lucas Ferreira Gomes ${ }^{1}$ \\ Universidade Tecnológica Federal do Paraná (Campus Londrina) \\ Eliane Maria de Oliveira Araman ${ }^{2}$ \\ Universidade Tecnológica Federal do Paraná (Campus Cornélio Procópio)
}

\begin{abstract}
Resumo
A presente pesquisa remete a uma reflexão a respeito do uso dos recursos oferecidos pelas Tecnologias da Informação e Comunicação (TIC), em especial, vídeos didáticos para o trabalho docente, visto que, cada vez mais, torna-se necessária a inserção das tecnologias no contexto escolar, a fim de se atender as necessidades da sociedade atual, na qual tais recursos estão cada vez mais presentes. Entende-se o uso de tecnologias como um elo importante entre professor, o conhecimento matemático e a compreensão dos alunos, sendo os vídeos didáticos uma das ferramentas que podem fortalecer esse elo. A proposta de baseá-los na História da Matemática se deve ao fato de que diversas pesquisas defendem que essa metodologia pode contribuir para a compreensão dos conceitos matemáticos, favorecendo, assim, uma reflexão a respeito dos tópicos explorados. Desta forma, ela visa a inserção de ambas no contexto escolar, a fim de que elas desempenhem suas contribuições na aprendizagem da Matemática. Neste contexto, o presente artigo tem como objetivo propor uma forma de se elaborar vídeos didáticos baseados na História da Matemática que possam ser empregados nas aulas de Matemática. Por fins didáticos, apresentamos esta proposta por meio de uma exemplificação: a produção de um vídeo sobre os conceitos relacionados ao estudo dos quadriláteros nas geometrias hiperbólica e elíptica, evidenciando os passos realizados na construção, além das orientações para o uso dos vídeos didáticos em sala de aula.
\end{abstract}

Palavras-chave: Educação Matemática; Vídeos Didáticos; História da Matemática; Geometrias Hiperbólica e Elíptica.

\footnotetext{
Abstract

${ }^{1}$ E-mail: lucasgomis@ @otmail.com

${ }^{2}$ E-mail: elianearaman@utfpr.edu.br
} 
This research refers to a reflection about the use of the resources offered by Information and Communication Technologies (ICT) from didactic videos to the teaching work, since, increasingly; it becomes necessary to insert the technologies in the School Context, in order to meet the needs of today's society, once these resources are increasingly present. The use of technologies is understood as an important link between teachers, mathematical knowledge and students' understanding, being the teaching videos one of the tools that can strengthen this link. The proposal to ground them on Mathematics History is because several researches supports that this methodology can contribute to the understanding of the mathematical concepts, in this way facilitating a reflection on the topics explored. That is why, it aims at the insertion of both in the school context, so that they accomplish their contributions in the learning of Mathematics. In this context, this article aims to propose a way to elaborate didactic videos based on Mathematics History that can be used in Mathematics classes. For teaching purposes, it presents this proposal by means of an example: the production of a video about the concepts related to the study of quadrilaterals in the hyperbolic and elliptical geometries, evidencing the steps taken in the construction, besides the guidelines for the use of the didactic videos in the room of class.

Keywords: Mathematics Education, Didactic Videos, History of Mathematics, Hyperbolic and Elliptical Geometries.

\section{Introdução}

A Matemática apresentada aos alunos no contexto escolar, na maioria das vezes,

é desvinculada de sua origem e de seus aspectos históricos, enfatizando-se os procedimentos e técnicas matemáticas, ao invés de uma reflexão sobre o surgimento destes conceitos (DEIXA; SALVI, 2014). Desta forma, seria necessário buscar elementos e estratégias que possibilitem aos alunos compreender como e quando esses conceitos surgiram, de modo que os estudantes possam compreender que a Matemática não é uma ciência na qual tudo está pronto e acabado, mas que muitas ideias foram criadas em épocas e contextos diferentes.

A História emerge como uma possibilidade de conduzir o aluno a entender as razões matemáticas, bem como os conceitos e os seus desenvolvimentos. Essa metodologia se caracteriza como uma fonte de investigação para as aulas de Matemática, que pode atrair os educandos, levando-os a reconhecer que todo conhecimento tem sua história, e que a Matemática é uma construção humana (GROENWALD, 2004).

Apesar dessas evidências, muitos professores não utilizam a História da Matemática em suas aulas, como destaca Feliciano (2006), ainda que os Parâmetros Curriculares de Matemática (1998) defendam o uso dessa metodologia. Muitos docentes dizem não utilizar, e, até mesmo, afirmam desconhecer tal proposta. Assim sendo, o autor destaca a necessidade de se incentivar a formação dos professores para o uso da História 
da Matemática, uma vez que alguns dos sujeitos investigados por ele diziam ter o interesse em utilizar, mas não sabiam como. Destarte, é possível compreender que, mesmo que os professores tenham interesse em elaborar aulas baseadas na História da Matemática, faltam recomendações e inclusive formação para seu uso (FELICIANO, 2006).

Todavia, Machado (2011, p. 16) defende que se pode "buscar apoio na História da Matemática para escolher métodos pedagogicamente adequados e interessantes para abordar determinados tópicos. Um destes métodos pode ser o vídeo”. E sua utilização justifica-se no fato de que hoje vive-se na sociedade da comunicação e da informação, na qual o conhecimento não é pronto e acabado, mas é um processo reflexivo e, ao mesmo tempo, dinâmico, considerando que necessita ser construído, refletido, apropriado e reconstruído sempre (MACHADO; MENDES, 2013). Isso faz com que as instituições escolares, bem como seus sistemas de ensino, adotem propostas educativas inovadoras, dinâmicas e criativas, capazes de contribuir para a formação dos sujeitos, independentemente do nível de formação que eles se encontram.

Mediante tais ponderações, o presente trabalho tem como objetivo propor uma forma de se elaborar vídeos didáticos baseados na História da Matemática que possam ser empregados nas aulas dessa disciplina. Assim, propomos o uso de vídeos baseados em informações históricas em que se exponha o desenvolvimento histórico dos conceitos matemáticos, sendo essa uma das possibilidades de se inserir esse conteúdo em sala de aula.

Para fins didáticos, apresenta-se uma exemplificação de como se produzir um vídeo baseado na História da Matemática, sendo ele sobre o desenvolvimento histórico de alguns conceitos referentes aos quadriláteros na geometria hiperbólica e na geometria elíptica.

\section{A História da Matemática e as suas contribuições para a formação do professor e para o ensino de matemática}

Entende-se que os conhecimentos advindos da História da Matemática podem trazer inúmeras contribuições para a construção do conhecimento e para a prática docente do professor de Matemática, sendo possível, a partir dela, compreender a Matemática como uma construção humana, assim como, as necessidades e os problemas que motivaram o surgimento de alguns conceitos matemáticos, além das conexões existente 
entre a Matemática e outras ciências, como a Filosofia, ademais de outros elementos (MIGUEL, 1993).

Por isso, é plausível compreender que o conhecimento dos elementos históricos dos conceitos matemáticos precisa fazer parte da formação dos professores para que tenham fundamentos que lhes permitam mostrar aos alunos a Matemática como ciência que não trata de verdades eternas, infalíveis e imutáveis, mas como ciência dinâmica, sempre aberta à incorporação de novos conhecimentos (BRASIL, 1997).

Nesse contexto, a História da Matemática na formação docente pode ser um caminho que auxilie na forma como ele irá atuar em sala de aula e, para tanto Miguel e Brito (1996) defendem a participação orgânica da história na Educação Matemática, isto é, os conceitos matemáticos na formação do professor devem ser, quando possível, explorados a partir de uma perspectiva histórica.

Além disso, ela deve ser inserida no ensino de Matemática pelos docentes, como destaca Katz (2008 - apud BISSI, 2015, p. 4) "é necessário apresentar aos alunos o desenvolvimento das ideias matemáticas, mostrando como a Matemática foi constituída de forma natural e que as ideias dos grandes matemáticos perduram até os dias atuais". Chaquiam (2015, p. 13) corrobora ao afirmar que os:

\footnotetext{
(...) estudos atuais apontam que a História da Matemática, combinada com outros recursos didáticos e metodológicos, pode contribuir para a melhoria do ensino e da aprendizagem da Matemática, emerge como uma possibilidade de buscar uma nova forma de ver e entender a Matemática, tornando-a mais contextualizada, mais integrada com as outras disciplinas.
}

Para tanto, é necessário entender que para a melhor compreensão da Matemática, em seu desenvolvimento atual, é importante considerar todo o processo com suas transformações e intenções de cada época e civilização. Por isso, de acordo com Jankvist (2009), a História da Matemática pode levar o aluno a entender como a Matemática evoluiu, como e quando os conteúdos foram surgindo e, também, o contexto no qual se deu a criação destes.

\section{Vídeos didáticos e a história da matemática}

Como já se destacou, vive-se na sociedade da comunicação, da informação e da aprendizagem coletiva, na qual o conhecimento não é estático, pois se modifica a todo o momento uma vez que é refletido e questionado. Isso exige que as instituições 
educacionais e os sistemas de ensino adotem currículos e propostas educativas inovadoras, dinâmicas e criativas e capazes de contribuir na formação de cidadãos críticos, criativos e comunicativos como sujeitos sociais (MORAN, 1995).

Compreende-se que, cada vez mais, a inserção das tecnologias no contexto escolar seja necessária na tentativa de atender as exigências da atual sociedade. Assim, a influência dos recursos tecnológicos na prática educacional é muito maior principalmente na disciplina de Matemática (BALDIN, 2008). Neste contexto, a elaboração e o uso de vídeos didáticos tem se mostrado como uma alternativa para inserção dos recursos digitais em sala de aula, que devido as suas potencialidades tem uma objetividade que pode contribuir para o ensino e para aprendizagem da Matemática. Como destaca Carvalho e Gonçalves (2000, p. 17) “as imagens do vídeo causam impacto e falam por si mesmas”. Além de ter uma dimensão moderna e lúdica (MORAN, 1995), sendo moderna pelo fato de ser um meio de comunicação atual e possuir várias linguagens; e lúdica, pelo fato de permitir brincar com a realidade.

Outro aspecto importante é que o vídeo é uma ferramenta pode ser acessada a qualquer hora e em qualquer lugar, tornando-se, assim, um poderoso recurso de informação. Também deve-se ponderar que o vídeo tem som, cores e movimentos, e isso pode prender a atenção do aluno.

Além desses aspectos, a História apresenta-se como uma fonte de informação para o ensino e para a aprendizagem da Matemática. E, como destaca Jankvist (2009), o conhecimento histórico desperta o interesse do aluno pelo conteúdo que está sendo ensinado. Nessa perspectiva, acredita-se que é possível aliá-la a outras estratégias pedagogicamente adequadas e interessantes para abordar determinados tópicos e o vídeo pode ser uma delas (MACHADO, 2011).

No que tange as atividades históricas e os vídeos voltados para o ensino de Matemática, Machado e Mendes (2013) defendem a investigação histórica como um princípio de aprendizagem visto que a exploração conceitual e didática do desenvolvimento histórico da Matemática traz múltiplos significados ao conhecimento construído em sala de aula. Segundo eles, as informações históricas devem enfatizar os porquês matemáticos que podem "ser explícitos em problemas suscitados nas atividades ou explícitos nos textos históricos resgatados de fontes primárias (textos originais, 
documentos ou outros artefatos históricos) ou secundárias (textos originais ou de livros de História da Matemática” (MENDES, 2010, p. 39).

Para Mendes (2001), é necessário que as atividades sejam sequencialmente planejadas para que, de forma gradual, possam contribuir para a construção do conhecimento matemático. Considerando tais aspectos, é possível entender que nenhum vídeo deve ser utilizado em sala de aula sem que tenha sido previamente explorado nos aspectos conceituais e pedagógicos pelo professor.

Assim, acreditamos que aliar os vídeos à História da Matemática seja algo possível, sendo que seu uso didático pode corroborar para uma aula mais dinâmica e prazerosa, auxiliando, dessa forma, na aprendizagem dos alunos de conceitos matemáticos explorados (MACHADO; MENDES, 2013; MACHADO, 2011).

\section{Aspectos metodológicos}

Consideramos a abordagem qualitativa a mais adequada para a pesquisa realizada. Segundo Bogdan e Biklen (1994), uma investigação de caráter qualitativo é descritiva e seu interesse maior está no processo de investigação, e não, apenas, nos resultados obtidos.

Além disso, para esses autores, neste tipo de pesquisa nada deve ser considerado como trivial uma vez que "tudo tem potencial para constituir uma pista que nos permita estabelecer uma compreensão mais esclarecedora do nosso objeto de estudo" (BOGDAN; BIKLEN, 1994, p. 43). Deve-se ressaltar que o mais importante "não é recolher muitos dados, mas recolher dados adequados a fim de que se tenha em vista, e que sejam de confiança" (PONTE, 2002, p.18).

Com o objetivo de se explorar a proposta do uso dos vídeos didáticos baseados em aspectos históricos de conceitos matemáticos que podem ser averiguadas nas aulas de Matemática, mostramos, neste trabalho, uma possibilidade de se produzir um vídeo didático. Para tanto, faremos uma exemplificação destacando os passos utilizados na produção do vídeo que aborda os quadriláteros nas Geometrias Não Euclidianas, especificamente nas geometrias elíptica e hiperbólica, fazendo uma comparação dessas com a geometria euclidiana plana.

Destaca-se que ele foi produzindo seguindo alguns passos. O primeiro passo foi a construção do referencial teórico que sustenta a presente proposta, sendo elas pesquisas 
que versam sobre a História da Matemática, uso e elaboração de vídeos didáticos e uma reflexão a respeito dos saberes docentes. Já o segundo passo foi o recorte do episódio histórico em que o vídeo se baseia, o qual foi desenvolvido a partir dos saberes docentes propostos por Tardif (2013), isto é, a partir dos saberes da formação docente, curriculares e disciplinares, que são apresentados mais adiante, é que desenvolvemos uma justificativa para os recortes. Logo, o terceiro passo da pesquisa foi a elaboração do roteiro ou script, transformando o episódio histórico na estrutura do vídeo, além da construção da animação que possibilitou sua produção. O último passo foi a gravação do vídeo e sua edição. Destaca-se que nesses dois últimos passos foram levadas em consideração as sugestões e/ou indicações para elaboração de vídeos, baseados em elementos históricos de conceitos matemáticos, propostos por Machado e Mendes (2013).

\section{Construção do vídeo didático}

Na busca de encontrar uma forma de se realizar o recorte de um episódio histórico que pudesse ser transformado em vídeo didático, procurou-se levantar na literatura subsídios para elaborar tal proposta, assim encontrou-se nos saberes docentes e suas tipologias, apresentados por Tardif (2013), elementos que possibilitaram fazê-lo.

Discussões que remetem aos saberes mobilizados pelos professores em sua prática pedagógica têm propiciado o desenvolvimento de diversas pesquisas, como Gauthier (2006) e Tardif (2013), entre tantas outras. Esses e outros pesquisadores defendem que a profissionalização da atividade docente deve identificar os saberes próprios do ensino, levando em consideração os contextos em que esses saberes se efetivam, visto que trazem uma marca muito forte para a ação desses sujeitos, influenciando nas tomadas de decisões, bem como nas escolhas realizadas.

Essas pesquisas também remetem a perspectiva de que os saberes docentes "formam uma espécie de reservatório" que o professor pode abastecer para atender as necessidades que a ação docente exige (GAUTHIER, 2006). Neste mesmo viés, Tardif e Gauthier (1996, p. 11) destacam que "o saber docente é um saber composto de vários saberes", os quais são responsáveis pela estruturação do conhecimento dos professores, e, por isso, influenciam em suas práticas.

Além desses aspectos, Tardif (2013) apresenta algumas tipologias de saberes docentes, e a partir destas tipologias, foi possível identificar, nos saberes da formação 
pedagógica, nos saberes disciplinares e nos saberes curriculares, elementos que possibilitaram realizar o recorte: aspectos relacionados a origem do conteúdo, bem como, orientações curriculares para tal conteúdo, ou seja, conseguimos destacar os seguintes aspectos:

- Os saberes da formação profissional: são constituídos pelas técnicas e métodos de ensino, assim em nossa proposta nos orientamos pelos aspectos metodológicos da História da Matemática, ou seja, antes de tentar fazer um recorte histórico o professor deve conhecer as orientações que esta, enquanto metodologia de ensino, propõe.

- Os saberes disciplinares: são compostos pelos conjuntos de saberes adquiridos pelos povos ao longo do tempo remetendo ao próprio conteúdo. Por conseguinte, para se realizar um recorte de episódios históricos, elenca-se que o professor deve saber o conteúdo a ser abordado, e, além disso, não se pode utilizar a História da Matemática sem deixar de investigar os aspectos históricos do conteúdo que se pretende abordar.

- Os saberes curriculares: São os saberes relacionados às orientações e às propostas curriculares. Dessa forma, destaca-se que para se realizar o recorte de episódios históricos, o professor deve compreender o que os documentos norteadores dizem a respeito do tópico que se pretende abordar, bem como se a metodologia HM pode ser empregada e julgar se com ela será possível atingir os objetivos previamente definidos.

Sob tal enfoque, apresenta-se o recorte realizado e sua justificativa seguindo como pressuposto:

- As orientações curriculares: o que defendem as Diretrizes Curriculares de Matemática do Estado do Paraná (2008) e os Parâmetros Curriculares Nacionais de Matemática (1997) a respeito das Geometrias Não Euclidianas e o seu ensino (vinculado aos saberes curriculares).

- Os fundamentos da história: os aspectos históricos das Geometrias Não Euclidianas (vinculado aos saberes disciplinares).

- As orientações metodológicas: o que dizem as pesquisas desenvolvidas sobre os aspectos metodológicos da HM para o ensino de Matemática (vinculado aos saberes da formação profissional.

Com efeito, foi possível sintetizar em um esquema os saberes que julgamos necessários para se realizar o recorte de episódios históricos: 
Figura 1 - Saberes necessários para o recorte de episódios históricos

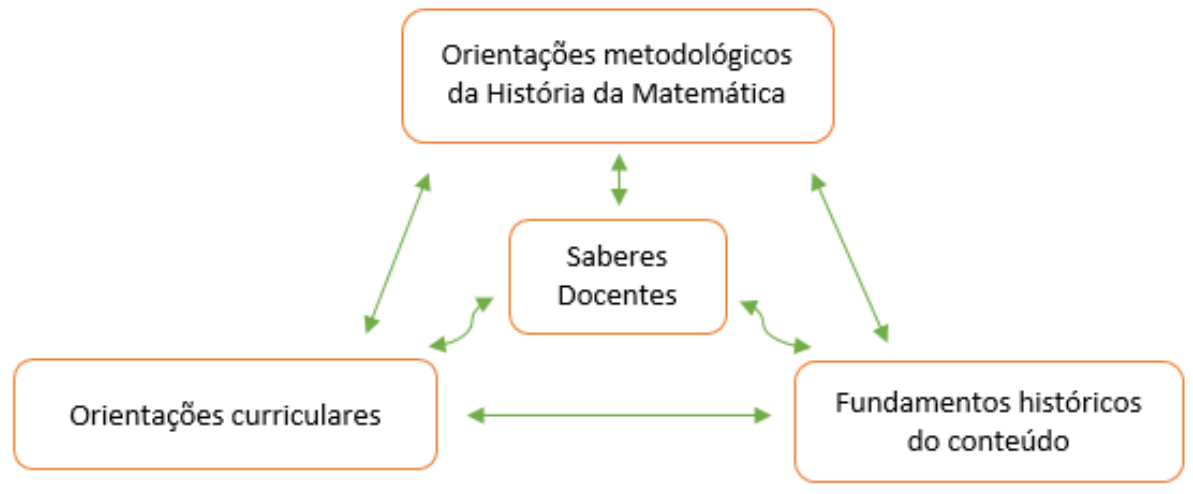

Fonte: Os Autores

Partindo de tais reflexões, apresenta-se, a partir deste momento como exemplar, o recorte do episódio histórico, bem como os passos realizados na elaboração do vídeo. Inicialmente, realizou-se o recorte do episódio histórico que foi desenvolvido por meio da estratégia apresentada anteriormente a partir das reconstruções históricas da origem das Geometrias Não Euclidianas realizadas por Barbosa (2011) e Ribeiro (2012). Segue o recorte:

\section{Quadro 1 - Recorte realizado}

O estudo dos quadriláteros nas Geometrias Não Euclidianas surgiu a partir das tentativas de prova do quinto postulado de Euclides por Giovanni Girolamo Saccheri (1667-1733) e Johann Heinrich Lambert (1728-1777) (BARBOSA, 2011).

Saccheri admitiu três hipóteses: dado um quadrilátero simétrico, o qual possui dois ângulos retos e os outros dois iguais entre si. Dessa forma, existem três possibilidades para esses ângulos, que ele chamou de ângulos de topo, a de ambos serem retos; ambos serem obtusos; ambos serem agudos (BARBOSA, 2011).

Saccheri conseguiu verificar a validade dos ângulos serem agudos, mas achou incompatível a ideia, já que este tinha como base de estudo o plano, ou seja, a geometria euclidiana. Ele também diz ter encontrado vários resultados estranhos. Algum tempo depois, com as ideias exploradas por Bolyai, Lobachevsky, Gauss, Riemann entre outros, foi possível entender que a medida desses ângulos irá depender da geometria considerada:

- Geometria plana: esses ângulos são retos.

- Geometria hiperbólica: esses ângulos são agudos.

- Geometria elíptica: esses ângulos são obtusos (RIBEIRO, 2012).

Já o quadrilátero proposto por Lambert, com o mesmo intuito, possuía três ângulos retos, investigando, assim, o quarto ângulo desse quadrilátero.

Uma vez que se conseguisse mostrar que esse também era um ângulo reto conseguiria provar que o postulado das paralelas poderia ser provado, mas assim como os outros ele não conseguiu (BARBOSA, 2011).

Da mesma forma que Saccheri, Lambert tinha três hipóteses para o quarto ângulo do quadrilátero: ser reto; ser obtuso; ser agudo. 
Ele queria chegar à conclusão de que a única possibilidade válida seria a do ângulo reto, buscando contradições para as outras duas hipóteses, pois assim conseguiria provar o quinto postulado de Euclides. Lambert conseguiu verificar que se os lados do quadrilátero fossem círculos máximos na superfície de uma esfera, a hipótese do ângulo obtuso era válida, assim muitos estudiosos falam que é possível que tenha motivado o trabalho de Riemann. Além de ter algumas ideias parecidas com as de Lobachevsky, dizendo em suas obras que fora da geometria euclidiana as suas ideias eram corretas (RIBEIRO, 2012).

Mais tarde, foi possível verificar que esses ângulos irão depender da geometria considerada:

- Geometria plana: esse ângulo é reto.

- Geometria hiperbólica: esse ângulo é agudo.

- Geometria elíptica: o ângulo é obtuso (RIBEIRO, 2012).

Além dessas propriedades, existem outras a serem consideradas em relação aos quadriláteros, como destaca Ribeiro (2012), que são consequências das propriedades vistas:

a) Na geometria Hiperbólica:

- A soma dos ângulos internos de qualquer quadrilátero é menor que $360^{\circ}$.

- Não existem retângulos, os quadriláteros terão no máximo três ângulos retos.

- O quadrado de lado unitário não pode ser empregado no cálculo de áreas, desta forma é utilizado um triângulo.

b) Na geometria elíptica:

- A soma dos ângulos internos de qualquer quadrilátero é maior que $360^{\circ}$.

\section{Fonte: Os Autores}

\section{Justificativas para o recorte:}

- Orientações curriculares: As DCE de Matemática (PARANÁ, 2008) defendem que conceitos elementares das geometrias hiperbólica e elíptica façam parte da formação do aluno, dentre esses conceitos ela remete as figuras geométricas, ângulos, triângulos, retas, paralelismo, etc. Nesse contexto, o estudo dos quadriláteros é um aprofundamento das ideias relacionadas às retas paralelas e ângulos, além de ter uma grande aplicabilidade na Matemática, como o cálculo de áreas.

- Fundamento histórico: O estudo dos quadriláteros e seus ângulos está profundamente relacionado às tentativas de prova do quinto postulado de Euclides, dentre os matemáticos que partiram desse estudo pode-se citar Giovanni Girolamo Saccheri (1667-1733) e Johann Heinrich Lambert (1728-1777), os quais chegaram em resultados muitos próximos dos que chegaram Lobachevsky e Bolyai, tempos antes de surgirem as Geometrias Não Euclidianas (RIBEIRO, 2012).

- Orientações metodológicas: O valor do conhecimento histórico não é ter uma bateria de histórias curiosas e históricas para entreter nossos alunos a fim de fazer uma 
paragem na estrada, pois a Matemática não pode se reduzir apenas a contar histórias, mas é necessário repensar a lógica da construção matemática, e isso só se faz se conhecendo primeiro as suas fontes (MACHADO; MENDES, 2013).

Partindo deste recorte, seguimos os passos propostos por Machado e Mendes (2013) para elaboração de vídeos didáticos baseados na História da Matemática:

\section{Título dos vídeos didáticos}

"O título a ser dado nos vídeos deve ser fruto da realização de um estudo e pesquisa sobre um determinado tema ou assunto que o represente de uma maneira geral" (MACHADO; MENDES, 2013, p. 95). Portanto, o título deve expressar qual é o foco principal dos vídeos.

Mediante tais apontamentos escolheu-se como título para o vídeo elaborado: "Os quadriláteros".

\section{Introdução}

"Trata-se na verdade de uma síntese ou resumo do assunto; é uma breve introdução ao foco do assunto e que destaca os aspectos mais importantes. Em suma, é o que vai atrair a atenção inicial dos alunos às vídeo-aulas" (MACHADO; MENDES, 2013, p. 96). Além disso, destacam que o importante é a brevidade.

Assim, buscou-se ser bem breve destacando apenas os conceitos que seriam explorados e o objetivo do vídeo.

\section{Storyboard}

"Desenho das tomadas e enquadramento de modo que se ajustem as realizações das fases anteriores [...] isso se faz necessário para garantir que as imagens usadas obedeçam àqueles conteúdos de que tratam as vídeo-aulas" (MACHADO; MENDES, 2013, p. 96). Em suma, essa etapa é o planejamento, bem como a organização do vídeo a ser desenvolvido, que neste caso foi a partir do recorte realizado. Para tanto, transformouse tal recorte no script, que é organização e a estruturação do vídeo:

\section{Quadro 2 - Script do vídeo}

Aparecer o avatar dizendo: Olá meu nome é Eugênio, neste vídeo vamos falar dos quadriláteros, destacando alguns conceitos que foram surgindo a respeito na geometria hiperbólica e na geometria elíptica ao longo do tempo.

Aparecer um quadro com as fotos: $\mathrm{O}$ estudo dos quadriláteros nas Geometrias Não Euclidianas surgiram a partir das tentativas de prova do quinto postulado de Euclides por Giovanni Girolamo Saccheri (1667-1733) e Johann Heinrich Lambert (1728-1777). 
Aparecer o avatar explicando no quadro: Saccheri admitiu três hipóteses, dado um quadrilátero simétrico, o qual possui dois ângulos retos e os outros dois iguais entre si, dessa forma existem três possibilidades para estes ângulos, que ele chamou de ângulos de topo:

Aparecer um balão com a foto das três hipóteses:

a) ambos serem retos;

b) ambos serem obtusos;

c) ambos serem agudos.

Aparecer o avatar explicando: Saccheri conseguiu verificar a validade dos ângulos serem agudos, mas achou incompatível a ideia já que tinha como base de estudo o plano, ou seja, a geometria euclidiana, ele diz ter encontrado vários resultados estranhos. Algum tempo depois, com as ideias exploradas por Bolyai, Lobachevsky, Gauss, Riemann entre outros, foi possível entender que a medida desses ângulos irá depender da geometria considerada:

\section{Aparecer o avatar explicando no quadro:}

a) Geometria plana: esses ângulos são retos.

b) Geometria hiperbólica: esses ângulos são agudos.

c) Geometria elíptica: esses ângulos são obtusos.

Aparecer o avatar sentado explicando: Já o quadrilátero proposto por Lambert, com o mesmo intuito, possuía três ângulos retos, investigando, assim, o quarto ângulo desse quadrilátero.

Aparecer a imagem: quadrilátero de Lambert.

Aparecer o avatar explicando: Uma vez que se conseguisse mostrar que este também era um ângulo reto conseguiria provar que o postulado das paralelas poderia ser provado, mas, assim como os outros, ele não conseguiu.

Da mesma forma que Saccheri, Lambert tinha três hipóteses para o quarto ângulo do quadrilátero:

\section{Aparecer um balão com a foto das três hipóteses:}

a) ser reto;

b) ser obtuso;

c) ser agudo.

Aparecer o avatar explicando: Ele queria chegar à conclusão de que a única possibilidade válida seria a do ângulo reto, buscando contradições para as outras duas hipóteses, pois assim conseguiria provar o quinto postulado de Euclides. No entanto, ele conseguiu verificar que se os lados do quadrilátero fossem círculos máximos na superfície de uma esfera, a hipótese do ângulo obtuso era válida, assim muitos estudiosos falam que é possível que tenha motivado o trabalho de Riemann. Além de ter algumas ideias parecidas com as de Lobachevsky, dizendo em suas obras que fora da geometria euclidiana as suas ideias eram corretas.

Aparecer o avatar explicando no quadro: Mais tarde foi possível verificar que esses ângulos irão depender da geometria considerada:

a) Geometria plana: esse ângulo é reto.

b) Geometria hiperbólica: esse ângulo é agudo.

c) Geometria elíptica: o ângulo é obtuso.

Aparecer no quadro: Além dessas propriedades, existem outras a serem consideradas em relação aos quadriláteros, que são consequências das propriedades vistas:

a) Na geometria Hiperbólica: 
- A soma dos ângulos internos de qualquer quadrilátero é menor que $360^{\circ}$.

- Na geometria hiperbólica não existem retângulos, os quadriláteros terão no máximo três ângulos retos.

- O quadrado de lado unitário não pode ser empregado no cálculo de áreas, dessa forma é utilizado um triângulo.

b) Na geometria elíptica:

- A soma dos ângulos internos de qualquer quadrilátero é maior que $360^{\circ}$.

\section{Fonte: Os Autores}

Como pode-se notar o vídeo foi realizado em forma de animação, para tanto utilizou-se o software Power Point, no qual as imagens foram animadas com efeitos visuais de entrada, saída, ênfase e transição, de maneira que dessem a impressão de movimento real. Alguns objetos foram programados para aparecer no momento em que desejávamos, bem como sair da apresentação e, por isso, o roteiro foi muito importante, pois a partir dele é que foi escolhido o que iria aparecer e em que momento, todavia sem a narração, como mostra a figura a seguir:

Figura 2 - Animação das imagens no Power Point

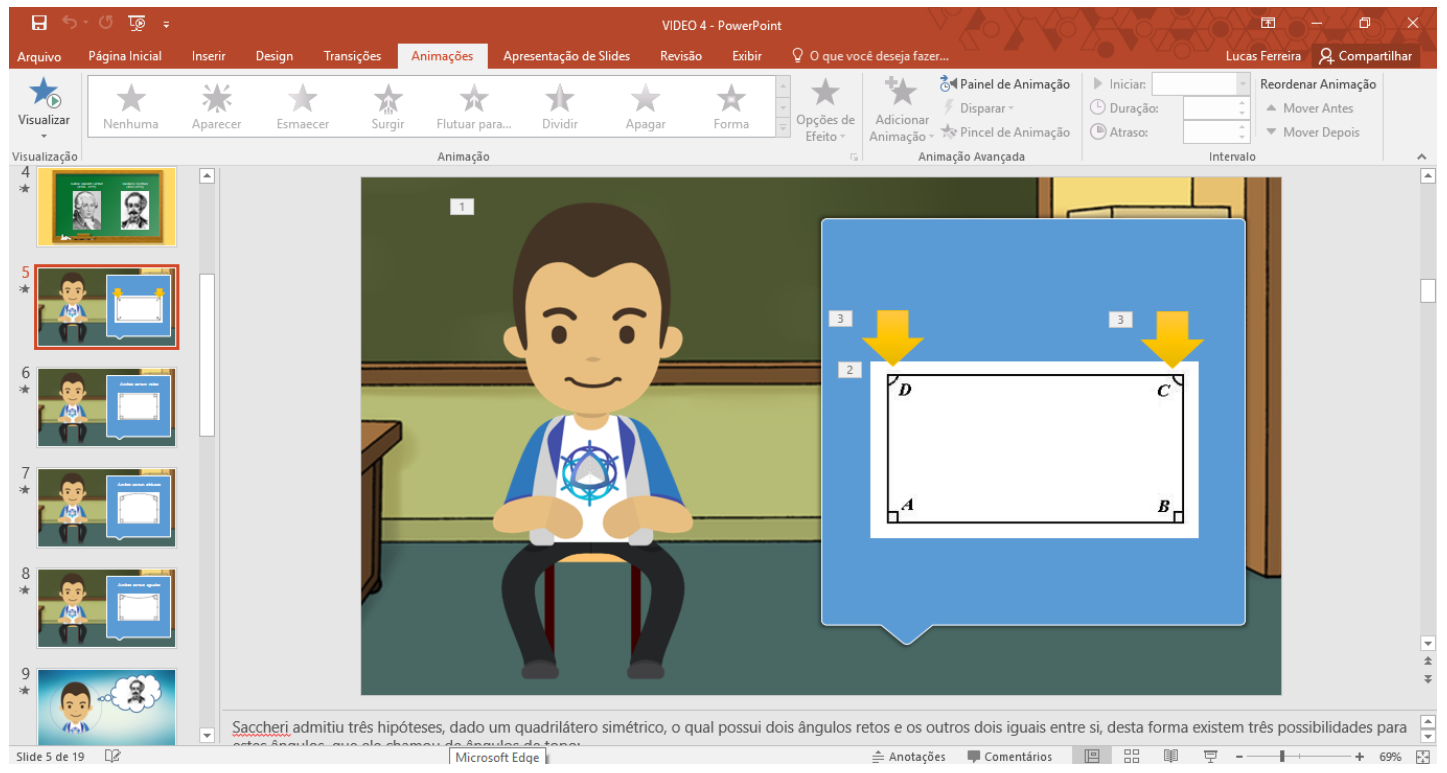

Fonte: Os Autores

Optou-se pela utilização de um avatar ${ }^{3}$, pelo aspecto visual, já que ele representa a ideia das Geometrias Não Euclidianas. Como é possível perceber na Figura 2, ele traz

\footnotetext{
${ }^{3}$ O avatar foi criado pelo aluno Elias de Moraes Fernandes, sob orientação do Prof. Dr. Alexandre Rossi Paschoal, dentro do grupo de pesquisa "Laboratório de Jogos Digitais: Desenvolvimento de Jogos e/ou
} 
em sua camiseta um logotipo que remete a tais geometrias, além disso, é possível inserir outros elementos, como ambientes e posições variadas, que dão vida ao vídeo.

\title{
4. Revisão e elaboração
}

Nesta fase, é necessário moldar as imagens e fazer as correções necessárias, além disso:

\begin{abstract}
Outra coisa a se fazer nessa etapa é a seleção musical que fará parte da trilha sonora do vídeo como background. Um cuidado a ser tomado é a seleção de uma música para cada etapa, atentando para seu tamanho: 10, 30, 45, 60 segundos ou mais, se necessário. É importante escolher um acorde com a música do filme, possivelmente, uma música sem palavras, para não sobreporse à voz do narrador ou do ator/palestrante/professor (MACHADO; MENDES, 2013, p. 97).
\end{abstract}

No que diz respeito ao vídeo elaborado, a escolha das músicas (trilhas) foi uma etapa em que dificuldades foram encontradas, pois era necessário tomar cuidado com essa escolha que deveria ser apenas trilhas livres de direitos autorais, ou seja, aquelas que já estão no domínio público ou trilhas brancas ${ }^{4}$. Por isso, optou-se por trilhas brancas por ter melhor qualidade e se ajustarem melhor ao que era pretendido, as quais são encontradas de diversos tamanhos, como 1 minuto, 30, 20, 15 e 10 segundos.

\section{Filmagem}

"Só agora, neste momento, procedem-se as filmagens. Devem aderir plenamente ao que está previsto. Isso apenas permite que o vídeo tenha um bom desenvolvimento" (MACHADO; MENDES, 2013, p. 97).

Em relação ao vídeo produzido, esta etapa foi desenvolvida após a conclusão das montagens das animações, e se deu a partir do software Camtasia Studio (Figura 3), que é um aplicativo que permite a gravação e edição de vídeos a partir da captura da área de trabalho do Windows, ou seja, ele permite gravar toda atividade realizada na tela do computador, além da narração que é feita simultaneamente a captura.

Aplicativos para Mobile \& Cia”, coordenado e desenvolvido por tal professor na Universidade Tecnológica Federal do Paraná - campus Cornélio Procópio.

${ }^{4}$ São trilhas sonoras livres, que não é necessário pagar pela sua utilização. 
Figura 3 - Gravação das imagens no Camtasia Studio

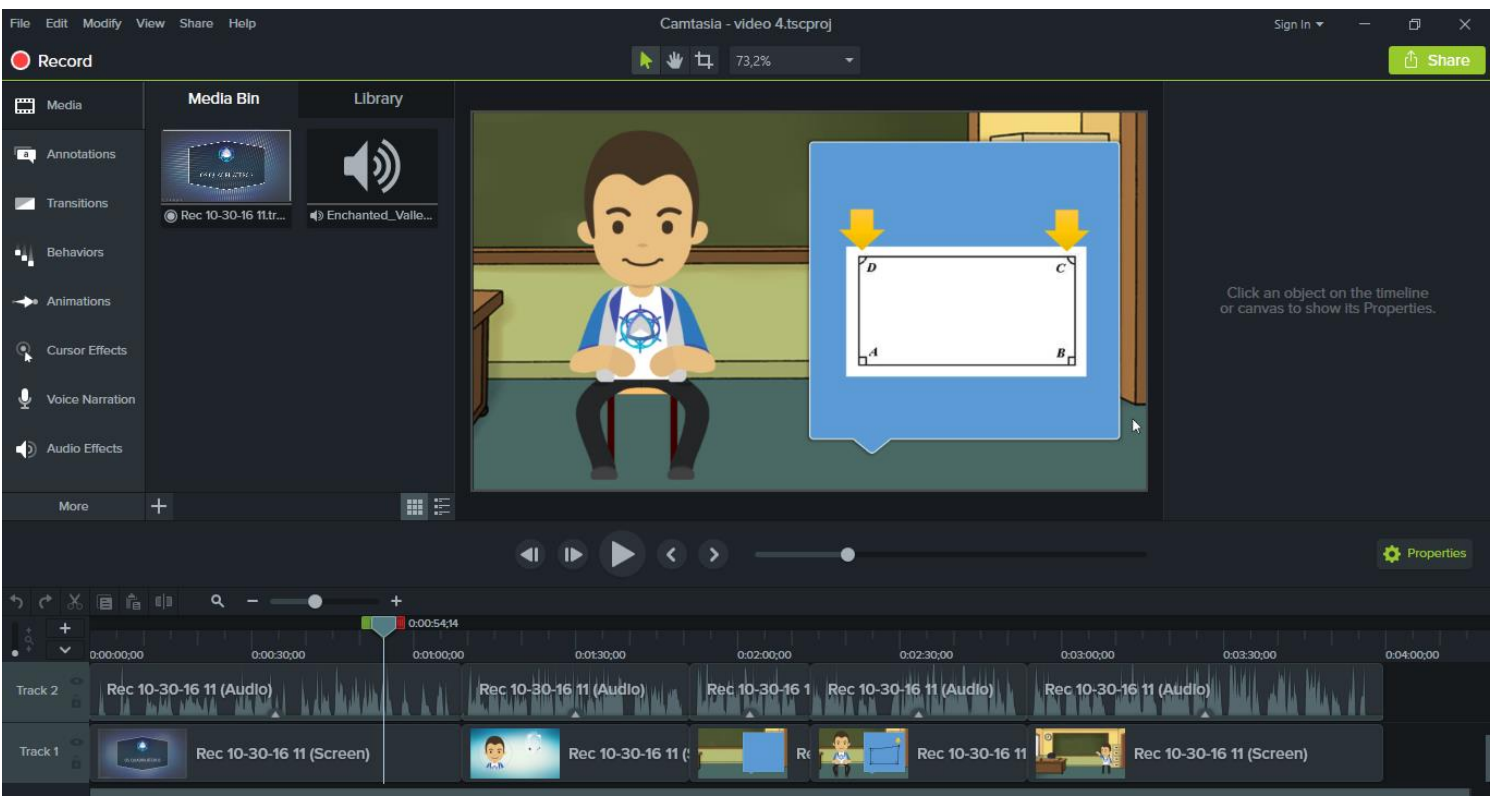

Fonte: Os Autores

\section{Edição Preliminar}

Depois que é feita a filmagem, os filmes devem passar por um processo de edição e montagem que "é o conjunto do vídeo, incluindo os efeitos e transições, que ajudam a linha narrativa do vídeo que está sendo feito. Nesta fase procedem-se cortes em partes de cada cena do vídeo, aparando os excessos preliminares, intermediários e finais" (MACHADO; MENDES, 2013, p. 97).

Nesta etapa, deve ser feita, também, a inserção do brackground, que é a inserção da música de fundo, que de acordo com Machado e Mendes (2013, p. 98): "não deve haver espaço com músicas em altura de som maior do que a voz do narrador, para não prejudicar o entendimento do texto. Deve haver sincronia entre imagens e sons para que o público possa relaxar e desfrutar do conteúdo do vídeo”.

\section{Edição final}

São os ajustes finais de sincronias, cortes ou prolongamentos de imagens ou áudio, bem como a maneira de como escolherá salvar seu arquivo. Se desejar publicar na internet, rodar em DVD ou outra mídia, atenção para o formato do vídeo. Isso é importante porque o tamanho final do arquivo deve ficar de acordo com as necessidades. Um vídeo que será compartilhado na internet não 
Antes destas duas etapas de edição (preliminar e final) serem realizadas, assistiuse o vídeo para identificar se havia algo para ser corrigido ou fazer alguns cortes necessários. Além disso, ambas as etapas foram realizadas com os recursos do software Camtasia Studio, que em termos de edição oferece a função de fazer zoom, adicionar áudio, criar efeitos de transição e limpar o som de ruídos. Com ele também é possível gravar os vídeos em qualquer formato comuns de multimídia: avi, swf, exe, flv, wmv, gif animed, entre outros.

Assim conseguimos produzir, editar e finalizar a elaboração do vídeo proposto que está disponível em: https://www.dropbox.com/s/r1sxwzyapgfbkyb/Untitled\%20Project.mp4?dl=0.

\section{Orientações pedagógicas para o uso de vídeos didáticos}

Antes de se utilizar um vídeo em sala de aula, alguns procedimentos devem ser considerados. Assim, além de se apresentar uma forma de se elaborar também se faz necessário expor alguns desses cuidados que devem ser tomados:

- Antes de tudo, o vídeo deve ir ao encontro dos resultados de aprendizagem desejados, isto é, o próprio vídeo deve falar por si só qual o motivo dele ser assistido (MACHADO, 2011).

- Deve-se proporcionar um foco para ver, ou seja, o professor deve dar aos alunos algo específico para procurar e ouvir no vídeo, que segundo Machado e Mendes (2013) estimula sua atenção e sua visualização.

- Antes de o professor apresentar o vídeo aos alunos, ele deve verificar se eles possuem o conhecimento prévio para assisti-lo, introduzir o vocabulário necessário e preparar o terreno para novos aprendizados (MACHADO; MENDES, 2013).

- Pausar, retroceder e explicar quando surgirem dúvidas que possibilitam aos alunos apontar detalhes, analisar o conteúdo e saná-las (MACHADO, 2011).

- O vídeo pode ser usado em diversas situações e com objetivos diferentes, dependendo da necessidade, tais como, introdução ao tema, confronto de ideias, recapitulação ou, até mesmo, fechamento de algum assunto (MACHADO; MENDES, 2013). 
A partir dessas indicações, é possível considerar que cabe ao professor, que irá produzir o vídeo, levar em consideração a finalidade com que ele será utilizado, antes mesmo de produzi-lo, pois é este objetivo que irá possibilitar a construção. No caso, o vídeo proposto na seção anterior tinha como pressuposto introduzir o estudo dos quadriláteros nas Geometrias Não Euclidianas, especificamente nas geometrias hiperbólica e elíptica, por isso a apresentação das ideais aliadas a seus aspectos históricos.

Além dessas reflexões, torna-se necessário ponderar que o vídeo, por si só, não é autossuficiente, isto é, ele deve estar alicerçado em um bom planejamento de modo que se tenha como intuito alcançar os objetivos almejados. Por isso, ele deve estar inserido em um conjunto de atividades que, de forma sequencial, possibilitem a produção do conhecimento por parte do aluno.

\section{Algumas considerações}

Nesta investigação sobre a elaboração e uso didático dos vídeos didáticos de História da Matemática, é possível dizer que tal prática pode contribuir para uma aula mais dinâmica e prazerosa por parte do aluno. Como destaca Machado e Mendes (2013) o vídeo poder ser um instrumento de ativação da aprendizagem em sala de aula devido a suas potencialidades, dentre elas "favorece a conexão entre as componentes intuitiva, algorítmica e formal" proposta por Mendes (2010, p. 40).

Machado e Mendes (2013) relatam experiências de elaboração e de uso destes vídeos, as quais, segundo eles, possibilitaram perceber que é algo viável e que traz implicações positivas para as aulas de Matemática. Todavia, eles ressaltam a necessidade de se testar o material em sala de aula, visto que é preciso considerar que os alunos têm comportamentos diversificados em cada turma e que, por isso, o professor deve ajustar os vídeos à realidade de seus alunos.

No que diz respeito a este trabalho, foi possível perceber que as técnicas utilizadas e propostas para produção de vídeos didáticos baseados na História da Matemática são de possível execução. Além disso, essa prática não exige recursos tecnológicos avançados, e que, por essa razão, pode ser desenvolvida por professores em suas aulas.

Pelo exposto, percebe-se que a seleção de material histórico, que, de forma didática, pode possibilitar a produção de vídeos, é algo possível. Aqui, foi encontrado nos 
saberes docentes um potencial para se selecionar episódios históricos a partir de uma reconstrução histórica já realizada.

A partir deste trabalho, buscou-se mostrar uma estratégia para se elaborar vídeos didáticos de História da Matemática, de modo que os professores tenham subsídios que lhes permitam produzi-los e utilizá-los, de tal modo que a História da Matemática seja inserida em sala de aula e que, assim, esta metodologia possa desempenhar suas contribuições para a formação dos alunos.

\section{Referência}

BALDIN, Y. Y. Uso de tecnologia como ferramenta didática no ensino integrado: Uma forma de educação continuada para professores de nível básico. In: CARVALHO, L. M.; FOSSA, J. A.; GIRALDO, V.; MOURA, C. A. de; NORONHA, H. (Org.). História e tecnologia no ensino da matemática, vol. 2. Rio de Janeiro: Ciência Moderna, 2008.

BARBOSA, L. N. S. C. de. Uma reconstrução histórico-filosófica do surgimento das geometrias não euclidianas. 2011. 58 p. Dissertação (Mestrado em Ensino de Ciências e Educação Matemática) - Universidade Estadual de Londrina. Londrina, 2011.

BISSI, T. Álgebra e história da matemática: uma proposta de ensino a partir da matemática do Antigo Egito. In: ENCONTRO BRASILEIRO DE ESTUDANTES DE PÓS-GRADUAÇÃO EM EDUCAÇÃO MATEMÁTICA, XIX, 2015. Juiz de Fora. Anais... Juiz de Fora: Universidade Federal de Juiz de Fora. 2015.

http://www.ufjf.br/ebrapem2015/files/2015/10/gd2_tiago_bissi.pdf. Acesso em: 12 mar. 2016.

BOGDAN, R.; BIKLEN, S. Investigação qualitativa em educação: uma introdução à teoria e aos métodos. Porto, Porto Editora, 1994.

BRASIL. Parâmetros Curriculares Nacionais: Matemática. Secretaria de Educação Fundamental. Brasília: MEC/SEF, 1997.

CARVALHO, A. M. P. de; GONÇALVES, M. E. R. Formação continuada de professores: o vídeo como tecnologia facilitadora da reflexão. Cadernos de Pesquisa, dez. 2000. Disponível em:

$<$ http://www.scielo.br/scielo.php?script=sci_arttext\&pid=S0100-5742000000300004 \&lng=pt\&nrm=iso\&tlng=pt $>$. Acesso em: 12 jul. 2007.

CHAQUIAM, M. História da matemática em sala de aula: proposta para integração aos conteúdos matemáticos. São Paulo: Livraria da Física, 2015. (Série História da Matemática para o Ensino). 
DEIXA, G. V.; SALVI, Rosana F. Dificuldade dos professores em exercício no uso da história da matemática como alternativa didática para o ensino da matemática. Revista Científica da UEM: Série Ciências da Educação, Maringá, v. 1, n. 1, p. 63-76, 2014.

FELICIANO, L. F. O uso da História da matemática em sala de aula: o que pensam alguns professores do Ensino Básico. 2006. 171 f. Dissertação (Mestrado em Ensino de Matemática) - Universidade Estadual Paulista. Rio Claro, 2006.

GAUTHIER, C. Por uma teoria da Pedagogia, pesquisas contemporâneas sobre o saber docente. Rio Grande do Sul: Unijui, 2006.

GROENWALD, C. L. S. Perspectivas em Educação Matemática. Canoas: Ulbra, 2004.

JANKVIST, U. T. A categorization of the "whys" and "hows" of using history in mathematics education. Educational Studies in Mathematics, Dordrecht, n. 71, p. 235-261, 2009.

KATZ, V. J. A história da matemática: uma introdução. Lisboa: Fundação Calouste Gulbenkian, 2011.

MACHADO, B. F. Video-aula de história da matemática: uma possibilidade didática para o ensino de matemática. 144 f. 2011. Dissertação (Mestrado em Ensino de Ciências Naturais e Matemática) - Universidade Federal do Rio Grande do Norte. Centro de Ciências Exatas e da Terra. Natal, 2011.

MACHADO, B. F.; MENDES, I. A. Vídeos didáticos de história da matemática: produção e uso na educação básica. São Paulo: Editora Livraria da Física, 2013.

MENDES, I. A. Ensino da Matemática por atividades: uma aliança entre o construtivismo e a história da matemática. 2001. Tese (Doutorado em Educação)Programa de Pós Graduação em Educação, Universidade Federal do Rio Grande do Norte. Natal, 2001.

MENDES, I. A. Atividades históricas para o ensino de trigonometria. In: MIGUEL, A., et al. História da matemática em atividades históricas. 2. ed. São Paulo: Editora Livraria da Física, 2009.

MENDES, I. A. A investigação histórica na formação de professores de matemática. Revista Cocar, Belém, v. 4, n. 7, p. 37-48, jan./jun. 2010.

MIGUEL, A. Três estudos sobre história e educação matemática. 1993. 274 f. Tese (Doutorado em Educação). Programa de Pós-Graduação em Educação, Faculdade de Educação Universidade de Campinas. Campinas, 1993.

MIGUEL, A. BRITO, A. J. A história da matemática na formação do professor que ensina matemática. Caderno CEDES, Campinas, v. 40, p. 47-61, 1996. 
MORAN, J. M. O vídeo na sala de aula. Comunicação e Educação, São Paulo, v. 2, p. 27-35, jan./abr. 1995.

PARANÁ. Diretrizes curriculares da educação básica de matemática. Curitiba: SEED, 2008. disponível em: http://www.nre.seed.pr.gov.br/irati/arquivos/file /matematica.pdf>. Acesso em: 15 fev. 2016.

PONTE, J. P. Investigar a nossa própria prática. In: GTI (Ed.), Refletir e investigar sobre a prática profissional. Lisboa: APM, 2002. p. 5-28.

RIBEIRO, R. D. G. L. O ensino das geometrias não euclidianas: um olhar sob a perspectiva da divulgação científica. 2012. 102 p. Dissertação (Mestrado em Ensino de Ciências e Matemática) - Faculdade de Educação, Universidade São Paulo, São Paulo, 2012.

TARDIF, M. Saberes docentes e formação profissional. Rio de Janeiro: Vozes, 2013.

TARDIF, M.; GAUTHIER, C. O saber profissional dos professores: fundamentos e epistemologia. In: SEMINÁRIO DE PESQUISA SOBRE O SABER DOCENTE, 1. 1996, Fortaleza. Anais... Fortaleza: UFCE, 1996. 